\title{
3 Stratification and Social Mobility: Patterns of Inequality among Maasai and Hindus ${ }^{1}$
}

East African pastoralists on both sides of Lake Victoria share a broad tradition of the northern origins of tall light-skinned ancestors who drifted southwards and came into contact with dark-skinned Bantu agriculturalists with different physical characteristics. In these traditions, those pastoralists who settled to the west of Lake Victoria imposed themselves as the ruling elites of ethnically stratified kingdoms. Among the Ruanda, for instance, Jacques Maquet identified four strata. ${ }^{2}$ These were firstly the ruling dynasty who claimed divine origin, secondly Tutsi pastoralists who provided the army and an aristocratic elite, thirdly Bantu Hutu agriculturalists who formed the majority of the population, and finally scattered Twa hunter-gatherers who were the aboriginal inhabitants of this area. The historical accuracy of this tradition is open to question, given the apparent degree of cross-breeding between these strata and the elitist influence of colonial rule prior to Maquet's study. However, the tradition was widespread among other kingdoms of the region, ${ }^{3}$ and it provides an alternative model of stratification to that of the Maasai.

On the other side of Lake Victoria, the plains towards the East African coast were ideal for cattle rearing, and successive waves of pastoralists from the north asserted their military superiority by edging one another out to take control of this valuable niche. The Maasai appear to have been the most recent wave of pastoral immigrants to occupy the area before this ethnic succession was frozen by the incoming colonial authorities at the end of the nineteenth century. Unlike Tutsi pastoralists in Ruanda, the Maasai held themselves aloof. Such links as they developed with their agricultural and hunter-gathering neighbours tended to be tenuous and sporadic rather than institutionalised. Their social order was based on a democratic principle according to men's age rather than on any notion of ethnic descent.

Rather than compare the Maasai age system with stratification in the inland kingdoms of East Africa, I propose here to direct my discussion to the classical Hindu system, offering a more reliable and wider variety of themes for comparison. This relies primarily on Louis Dumont's detailed analysis (1972), which suggests some

\footnotetext{
1 This chapter is an abridged and revised version of the English original that was translated into French and published as 'Homo Hierarchicus et Homo Ascendens' in Abéles, M. and Collard, C. (eds.), 1985, Age, Pouvoir et Société en Afrique Noire, Karthala, Paris. (pp. 171-195). I am grateful to Karthala Presse for permission to draw on this here.

2 Maquet 1961: 10-12, 109, 124-5

3 Southall 1953: 5-6; Fallers 1956: 27-30; Hertefelt, 1962; Taylor 1969: 13-16; Beattie 1971: 23-26. Smith (1992: 77-98) outlines the archaeological evidence for the expansion of pastoralism into East Africa from the north.
} 
fundamental parallels despite his claim concerning the incomparable uniqueness of the Hindu system and the fact that his attempt at cross-cultural comparison is confined to the contrast between Indian and Western - homo hierarchicus and homo aequalis - leaving other forms of social stratification outside his scheme.

This is to use comparison as an analytical tool in its own right, showing how a number of component parts of Dumont's model can be rearranged, rather like pieces of a jigsaw, with the addition of some new pieces. This leads to a model of a very different type of society where age organisation is as important to an understanding as varna and caste are in India. While the Maasai are considered as my prime example of age stratification, the argument could extend to other age-based societies in region more generally, including the Samburu.

\subsection{Comparing Incomparables}

Initial comparison provides a contrast of principles. As a first approximation, caste in India involves a system of stratified groups characterised by fundamental immobility. From the male point of view, every man is constrained during his lifetime to remain with his caste group at the level into which he was born. Whereas age organisation entails a system of stratified groups with inevitable mobility - every man who lives long enough is promoted systematically with his age peers from the lowest group at initiation to the most senior, rather as classmates in a school are systematically promoted through successive grades as an undifferentiated group. To revert to the earlier analogy, each age-set of peers may be seen as passing in a queue up a ladder, and each rung is identified with a certain status or age grade (warrior, elder, etc). It is when one turns from the fundamental contrast between caste and age systems to the elaborations of each system, that one may also discern some intriguing parallels. The argument, then, is not that age organisation in East Africa should be regarded as a 'caste' system, but rather that it is an alternative type of hierarchy in which men ascend in their own lifetime, and it deserves as full a consideration in its own right as others have devoted to the caste system in India.

In the first instance, one may compare varna - the basic divisions of the Hindu hierarchy - with age grades among such East African societies as the Maasai. For Dumont, varna is an ideal type, a model that is universal throughout Hindu society and provides the ideological firmament upon which the caste system developed with regional and local variations. Its structure is expressed through a set of ascending binary oppositions that distinguishes each level from its superiors in terms of increasing purity: the Untouchables were outside the classical varna and their superiors were all inside; at the next level, the Shudras featured in the classical system, but contrasted with their superiors in having no 'dominion over animals' and 
not being 'twice born'; at the next level the Vaishyas enjoyed these privileges, but had no 'dominion over men', and so on. ${ }^{4}$

Age grades in East Africa may be similarly characterised by a ranked series of oppositions. Uninitiated boys are regarded as untamed and outside the age system. They only place their foot on the bottom rung of the age ladder at initiation. The Karimojong (distant neighbours of the Maasai) provide a striking example where an extended delay in initiations led to a serious build-up of lawlessness among 'boys' who could not be controlled by their seniors. It was this crisis that precipitated the initiations that brought them into the system and more firmly under the control of the elders. They were now actually on the age ladder. ${ }^{5}$

Among Maasai, boys as individuals are the principal and trusted family herders, but when they meet in pairs or small groups, they are popularly characterized as liars, thieves, and lacking any sense of respect. No boy would be allowed to control the cattle he inherits from his dead father until his initiation into warriorhood as a morani. From this point, he is at least on the lowest rung of the age ladder and may manage his own inherited stock. Associated with the glamour of warriorhood, he is expected to cultivate a certain finesse and a sense of responsibility and is under the more direct control of the elders. In Dumontian language, a morani enters fully into the system, and he acquires a qualified 'dominion over animals', which is denied to uninitiated boys. However, he is still structurally opposed to the elders on the higher rungs, who may marry and shoulder domestic responsibility. As a warrior, a morani remains a bachelor associated with the bush and he avoids the elders' villages in specific ways. Further elaborations of the system expressed as a series of structured oppositions will become evident in the course of the argument. At this stage, I would simply note that the more elaborate ceremonies for which the Maasai are renowned may be regarded as transitional rites that mark promotions up the ladder and a transformation across some binary opposition: boys leave boyhood on initiation to become moran, and so on.

However, unlike herd ownership, the task of herding cuts across the age and sex divisions of Maasai society. The small Maasai herdboy learning his craft among the calves close to the village, moran visiting their father's homestead, elderly men meeting their homecoming herds in the evening - and even women when necessity demands - may all share in this domain. This compares directly with agriculture in India, which is accessible to virtually everyone because it has a ritually neutral position and no association with impurity. ${ }^{6}$

4 Dumont 1972: 106

5 Dyson-Hudson 1966: 198-9

6 Dumont 1972: 137 


\subsection{Maasai Concepts of Purity}

Dumont's analysis hinges on the Hindu concept of purity as the ideological base of their caste system, which extended to a sophisticated division of labour. This is not an unfamiliar concept among the Maasai. Their blacksmith families were despised for the filth of their occupation and they were segregated in separate villages, intermarrying among themselves. However, they comprised only a fraction of one-percent of the Maasai population, and to this extent their position can hardly be compared with more fully developed Hindu caste system where untouchables occupied a similar pariah status. Beyond this, the division of labour associated with Hindu caste distinctions was of a quite different order to that found among the Maasai, where it was confined solely to the distinction between nomadic pastoralists and settled blacksmiths in an otherwise undifferentiated society.

The notion of purity does not define the Maasai age system. However, it does have an oblique relevance. Among adult Maasai men, and especially among moran, there is a general distaste of domestic filth associated with married women. Women are felt to contaminate meat when they prepare it in their huts, and they are allocated certain cuts that are generally despised by men. Child-bearing women in particular are thought to smell, partly because of the fat that they smear on their bodies, but especially from the excreta of their infants which foul their cloths. In the months following birth, this pollution is exaggerated by the custom that prohibits mother and child from washing, and this practice is repeated in the months following initiations for either sex. In this state, they are what may be described as 'ritual weaklings', especially vulnerable to vaguely defined dangers, and yet enjoying a unique closeness to God and a divine protection. There is a general belief that to wash during this period would wash away this protection and expose them to unnecessary danger. Thus at the most polluted end of a scale of purity, one has the notion of weakness, vulnerability, and ritual separateness. At the other end, the extreme of purity encompasses the ideal of moranhood. The association of the moran with the bush is partly expressed as an avoidance of the pollution of married women and ritual weaklings, especially where eating meat is concerned. Moran would not eat meat that has been seen by a married woman, and wives are expected to avoid areas where they might stumble across a group of feasting moran. Girls may accompany the moran, but they must keep their bodies and their cloths fresh and uncontaminated from the sort of organic by-products that pollute married women. It is sometimes said that the mere smell of a married woman would make a moran want to vomit.

There is an underlying contradiction in this ideal of purity. Moran are popularly held to have a penchant for adultery and hence for the most intimate bodily contact with married women. This is a controversial issue, thoroughly disliked by the elders, and despised by the girls who resent this hypocrisy among their boyfriends, and they will spurn the adulterers if they find out. Not every moran indulges in this polluting pursuit, and those who wish to display the supreme virtues of warriorhood will avoid married 
women in every respect, and even avoid less fastidious moran, claiming that they can smell the bodily contamination of their adulterous colleagues. These pure or chaste moran prefer to keep their own sweet smelling company, and even try to avoid intimate contact with their girls, sleeping beside them, but separated by a log. They associate their chaste and unadulterated purity with virility in war. The romantic self-gratifying adulterer cannot at the same time sport himself as the supreme, renouncing warrior.

With the advent of elderhood, when men marry and reconcile themselves to a measure of domestic pollution, those with more pride never quite relax into this condition, and all of them retain a certain aversion for meat cooked by women. However, they can no longer claim the purity of warriorhood nor its physical supremacy ever again.

The profile of pollution for each sex is represented diagrammatically in Chart 3.1 with reference to a scale of 'purity', with boys and old women somewhere in the sexless middle of this range.

Chart 3.1: Maasai notions of purity associated with age and sex.

\begin{tabular}{lll}
\hline & MALE DOMAIN & FEMALE DOMAIN \\
Pure & $\begin{array}{l}\text { chaste moran (true warriors) } \\
\text { moran who associate with girls }\end{array}$ & girls (who associate with moran) \\
& adulterous moran & \\
$\uparrow$ & & \\
$\downarrow$ & $\begin{array}{l}\text { Elders who freely cohabit with } \\
\text { married women }\end{array}$ & (old women) \\
& $\begin{array}{l}\text { male ritual weaklings (infants } \\
\text { and initiates) }\end{array}$ & $\begin{array}{l}\text { female ritual weaklings (infants, } \\
\text { initiates, and their mothers) }\end{array}$ \\
\hline
\end{tabular}

In this diagram, the path along the pure-polluted scale for either sex in the course of a lifetime would trace out a series of loops (from infancy to boyhood, back to initiation, up to warriorhood, and so on). In terms of relative status there is a clear pattern whereby purity is associated with physical strength. Those moran with the strongest claims to warriorhood are at the summit; and at the other extreme are the weakest and most vulnerable sectors of society who are treated as ritual weaklings. Blacksmiths and their wives and families might also be placed at the foot of this chart. However, this polluted status relates to their craft and not to age, and it can only be reversed over several generations when their descendants abandon blacksmithery. 
This scale is reflected in a variety of associated beliefs. With reference to Maasai concepts of health and disease, there is a prevalent notion that illness can be cured by purgatives and emetics to discharge the polluting substance from ones inner system. In this way, invalids, another weak and vulnerable sector of society, are felt to have some impurity that has to be discharged. At the other end of the scale, the moran are highly regarded for maintaining their inner systems in a constant state of expurgation by means of various roots they put into their soups, and they are regarded as the most evacuated and uncontaminated sector of society. Expressed in religious terms, this scale is reflected in a widespread convention in warfare that extends to other language groups in the area and is probably unique in its extensiveness in the region. This is a tenet that no warrior should kill a ritual weakling - that is any initiate or a nursing mother and her child or any women who might be pregnant. To do so would be to face the threat of unending disaster: they are protected by God. It is once again an opposition between the dangers of the bush, primarily associated with the warriors, and the protection of the village to which ritual weaklings and human reproduction tend to be confined. At a very pragmatic level, one has a cluster of beliefs that serve to protect the weakest sector of society on whom the future rests, and to keep amorous moran away from receptive wives. It is the elders, with most to gain from peace and warrior chastity, who are the principal guardians and propagators of these traditions.

The Maasai of each tribal section have their own Prophet to advise them on ritual precautions to thwart sorcery, notably by some unbelievably perverted elder. In the past, it was held to be the successful Prophets who were behind the successes of moran in their raiding. The link between these persists, and the Prophet now requires moran to help him root out the sorcerers. Moran are pure and gregarious, and they would never be suspected of sorcery: the image of a sorcerer is one of utter isolation. However, like the grazing cattle given to the Prophet, moran are held to imbibe the secrets of the bush and of sorcerers hidden in the bush as they traverse their manyata territory in all directions. They are too pure to understand these mysteries, but the secrets of these mysteries are revealed in their singing before the Prophet, enabling him to advise his clients on ritual matters. In terms of the scale of purity, disgruntled sorcery is located towards the bottom of the scale, while holding it in check is located towards the top, associated with the innocent 'play' of moran.

\subsection{The Two Arenas as Alternative Modes of Production}

The purity of the moran and their association with warriorhood is reminiscent of the Kshatriya caste who could claim 'dominion over all creatures' - except the Brahmans at the summit of the Hindu hierarchy. Certainly, the Kshatriya elite correspond broadly with the Tutsi, who held a similar military and administrative role in Ruanda. However, among the Maasai this combination of roles is divided between two sets of 
values associated respectively with the arenas shown in Figure 2.2: warriorhood and short-term gains, as opposed to elderhood and long-term interests.

Military prowess is associated with past claims to glory, and it remains an ideal in Maasai self-presentation. Rather than posit some 'pastoral mode of production', which has always proved elusive, it is useful to identify two modes with contrasting notions of property and relations through property: a predatory mode that relies relying on cattle raiding, and a herding mode that relies on peaceful husbandry. The analysis then hinges on the articulation between these two modes, notably the defence of their herds from raiders which is a prime responsibility of the manyat warrior villages.

So far as the pre-colonial scene was concerned, there is little doubt that the Maasai were successful predators; however peaceful husbandry would appear to have been a more efficient manner of increasing their herds. At a guess, each morani would have had to acquire 20 cattle each year to compare with the more successful years of peaceful breeding, whereas it would have been a quite outstanding warrior who managed to acquire even half that number by raiding in his whole career as a morani. ${ }^{7}$ In fact, while the image of predatory Maasai moran evidently dominated the wider region during the nineteenth century, most of our knowledge of that time concerns their civil wars, when the gains of one Maasai tribal section would have been the losses of another, and the overall benefits of warfare for the Maasai as a whole would have cancelled each other out. Altogether more significant would have been the role of the moran as diligent defenders of their own territories and herds, and it is this role that is stressed by the Maasai today.

It seems that the predatory mode of production, especially at times of famine, epidemic and territorial expansion, would have cast the moran as controllers of the means of production and would have diminished the status of elderhood. Certainly, at times of unrest, the elders had less than firm control over the moran. However, in terms of its material promise, it appears to have been the herding mode of production that was dominant through peaceful husbandry. It was clearly the elders who asserted their control both as stock owning household heads and as the puppeteers of the age system. The moran, it is true, regarded their defensive role as vital in this mode; but the elders' ready response was that they too had fulfilled this role in their time, and without them there would now be neither territory nor herds to defend.

If the moran could claim to share in the 'dominion over animals', and even to have a commanding position when it came to captured animals, it was the established elders who had sole claim to 'dominion over all creatures', that is over their wives and children as household heads, and over the age-set of moran through the firestick

7 Using data collected among the Samburu (Spencer 1965:320, 1973:10), I estimate that each fully active age-group of moran (ie. right or left-hand side) would comprise about $6 \%$ of the total population. With, say, about 12 cattle per person and a maximum growth rate through husbandry of about $10 \%$ p.a., the natural growth rate per active moran would be 12 × $10 \% \div 6 \%$, or 20 cattle per year. 
relationship. In the hierarchy of symbolic oppositions, this places firestick patrons on a par with the Kshatriyas of the Hindu system. ${ }^{8}$

Thus, just as it is not possible to equate Maasai concepts of purity with Hindu purity, so one must avoid equating Maasai moran parading their privileges with the Kshatriyas as an equivalent warrior stratum whose legitimacy to rule relied on superior force. It is the Maasai elders and not the moran that form the ruling elite with judicial authority, wealth, and control over the dominant mode of production to an extent that the moran with their subsidiary mode only rivalled in legend.

Whatever the articulation between these two modes may have been in the unsettled past, the authority of the firestick patrons remains a central theme of the major age rituals of the present. In other words, age-set ceremonies tend to focus on the unquestioned and ultimate power of the older men, imposing their will on young men in their physical prime, taming them by degrees into elderhood. There is a moral boundary between the two modes, as between rungs on the age ladder, which is bridged through ritual - under the control of elders.

\subsection{Rivalries between Adjacent Age-sets}

In considering parallels between the two societies further, it is necessary to extend the discussion from age grades to age-sets, and from varna to caste. ${ }^{9}$ As a reasonable approximation one may point out that:

age-set : age grade :: caste : varna.

Up to this point, the Maasai system has been presented primarily in terms of age grades, in other words as rungs on the age ladder that provide the hierarchy of statuses for age-sets of men as they climb upwards. Most societies have some form of age grading. Where there are age-sets, however, then this implies that people (males in this instance) pass up from rung to rung as groups in succession, and not separately as individuals at different speeds. It is the existence of age-sets among the Maasai that makes them so readily comparable with the castes of the Hindu system; and beyond this there are the corresponding divisions into sub-age-sets and subcastes and local variations.

One may first consider the distribution of power. Dumont notes that a man can only hold uncontested authority in relation to inferior castes. Within a caste, there is an ideal of equality that does not preclude the factionalism noted in various Indian studies. The premise of equality is also basic to the concept of age-set unity among the Maasai, with an emphasis on sharing food especially in moranhood and even 
extending in elderhood to certain sexual rights in each other's wives. Factionalism as such is not a marked characteristic of age-sets in elderhood, although among the moran at least, there is a certain competition for prestige and the occasional eruption of feuding. However between age-sets, as between castes, the senior can always claim a higher status and authority. ${ }^{10}$

This authority, however, may never be wholly conceded between adjacent agesets and a residual rivalry between such age-sets may be compared with local rivalry between adjacent sub-castes in India. Unlike the caste system, there can be no question of one age-set jostling its predecessor for seniority, but a similar ambiguity exists. From different positions on the age ladder, it is as if they are kicking at one another for moral advantage and for possession of the rungs rather than seeking to draw level or to overtake. A good example of this occurs when boys try to harry the moran for the privileges of moranhood. Then as youths after initiation onto the lowest rung, they covet the privileges attached to the second rung, while the moran who sport the privileges refuse to be harried for as long as possible.

When the moran retire from the limelight as outworn warriors and become novice elders, the rivalry with their successors does not end at this point. Because moran respect their immediate predecessors less than more senior men, they are less discreet in their adulteries. Suspicion and fury build up among the novice elders who become increasingly aware that their successors are still harrying them by trespassing on their domain, seducing wives who were previously lovers of the moran before being snatched away in marriage.

Rivalry between adjacent age-sets persists into elderhood. While the novice elders resent the trespassing moran, they are poised to challenge the authority of their adjacent seniors who, as 'firestick' patrons of the moran, occupy a commanding rung higher up the ladder. The more they can discredit the competence of these patrons to control the moran the more convincing their desire to speed the movement of age-sets up the ladder. Thus, while age-sets do not degenerate into factionalism after moranhood, relations between adjacent age-sets are characterized by respect for seniority tinged with suspicion, jealousy, barely concealed abuse, and even veiled gossip hinting at sorcery. A pattern that was established when the boys first filched the privileges of moranhood persists. As youths they eventually snatch the privileges of moranhood from their seniors; as moran they seduce the seniors' wives; and then as novice elders they still regard themselves as more virile in challenging the competence of their seniors on the firestick patrons' rung.

The idiom of respected elderhood as opposed to virile warriorhood is expressed in a variety of domains. Ritual belief points to the power of age seniority associated with a potent curse, but also to the vulnerability of old age and avoidances that are haunted by the fear of premature senility. In gossip, there is on the one hand the

10 Dumont 1972: 207, 228-9 
constant grumbling at the gross disrespect shown by 'boys' and 'moran' as terms that may be applied disparagingly to any male younger than the speaker. On the other hand, there is a recurrent joke depicting some trivial incident in which the butt is imitated with a high piping voice, like some bewildered old man, losing control, losing his head, and hence losing face. These two idioms are the thesis and antithesis of daily life, and apply especially to relations between adjacent age-sets.

More specifically, there are two rungs of moranhood on the age ladder: the lower rung is occupied by the age-set of initiated youths who are still denied the privileges of moranhood; and the upper rung is occupied by the age-set of senior moran who parade these privileges. Correspondingly, there are two age-sets of firestick patrons responsible for these age-sets of moran, junior and senior, and these occupy adjacent rungs higher up the ladder. In the course of the age-set cycle, rivalry between these age-sets becomes marked when each of these rungs is occupied by an age-set, with junior moran harrying senior moran, and junior firestick patrons harrying senior firestick patrons. Once the junior moran seize the privileges, promoting themselves onto the next rung and forcing the senior moran to climb up to novice elderhood, the more senior age-sets of elders step up to the next rung. From this point, the rungs associated with junior moran and junior firestick patrons remain unoccupied and rivalries between age-sets become dormant until the next age-set cycle (Figure 2.3). This pattern varies between tribal sections and appears especially a characteristic of southern Maasai more generally, with rivalries between age-sets that encourage a tacit alliance between moran and their firestick patrons - a 'firestick alliance' defending their positions on the ladder. This is so intense among the Kisonko Maasai in the south that each firestick alliance has a separate Prophet to protect them from the sorcery of the other during periods of change-over. Whereas in the north (and among the Samburu), there is a closer adherence to a gerontocratic model that focuses especially on a contest between age grades and the problem of controlling the moran. Here, the firestick patrons assume their role as feared disciplinarians on behalf of all elders rather than as natural allies of their moran protégés in the jostling between age-sets.

Paraphrasing Dumont: 'Each [age-set] will try to manipulate this situation to its own advantage, but other [age-sets] may be of a different opinion.' While with regard to the total pattern: 'It can be seen that a fundamental opposition which is conceived as the essence of a whole series of concrete distinctions really underlies the hierarchical order.'11 The present analysis takes the argument one step further by extending the principle of opposition beyond focusing on a single polarised ideology to a model in which there is interplay between two ideologies that are opposed as inversions of one another. It presents a pattern which among the Maasai highlights 
the contradictions of ageing, for youths on the one hand and for mature elders on the other.

\subsection{Status, Power, and the Premise of Respect}

The principal thrust of Dumont's argument relates to the separation of status and power in the Hindu system. The Brahmanic priests rise above the jostling for power at lower levels, and in this respect they may be compared with the oldest Maasai men who retain a venerable status as the prime repositories of Maasai tradition and have the most potent general blessing. They also have an informed detachment that often gives an air of absolute wisdom to their advice. Maasai is a society where one can speak of the charisma of old age. Just as Dumont suggests that the Brahman transcends the administration of this world and by detaching himself from power and the murk of politics, legitimizes his own superior status, so the oldest Maasai men, whose age-set has retired from active participation in local affairs, enjoy a similarly enhanced status. $^{12}$

Thus while Dumont notes the separation and subordination of power to status as though it is an unusual features that characterises the caste system, this feature also applies to the Maasai. To Dumont's argument, one might perhaps add that at each level, the seniors seek to maintain status superiority over their juniors, only to find themselves obliged to fight in a power struggle that belies their claim to status. Only when they finally and irrevocably lose in the struggle for power with the onset of old age do they acquire an incontrovertibly superior status.

Returning, then, to the ideological base of the Maasai system, one may say that their concept of purity (Chart 3.1) is closely associated with the predatory mode of production in which the moran have a commanding role, and while this may not have been the dominant mode traditionally, it retains its glamour. In so much as the herding mode of production was dominant, one has to turn to a different ideological base that underpins the primacy of elderhood and it is this mode that bears the more striking comparison and contrast with Dumont's analysis. This is illustrated in Chart 3.2 .

If it is necessary to begin with the ideological premise of purity in order to understand the Hindu varna, then in order to understand the dominant Maasai model one has to begin with the premise of respect. The Brahman transcends the remainder of society by having greatest purity, while the oldest men among the Maasai are held to have the most respect. This is no mere façade of 'respectability'. Rather it is envisaged as an ingrained 'sense of respect' which leads older men in particular to respect one another and their social obligations generally, and

12 Dumont 1972: 114, 212 
Chart 3.2: Ranked scales of status among the Maasai and Hindus.

\begin{tabular}{|c|c|c|c|}
\hline \multicolumn{2}{|c|}{ MAASAI SYSTEM } & \multicolumn{2}{|c|}{ HINDU SYSTEM } \\
\hline Age-set feature & Status ranking & Caste feature & Status ranking \\
\hline Supreme respect & $\begin{array}{l}\text { Oldest surviving age- } \\
\text { sets }\end{array}$ & Supreme purity & Brahmans as priests \\
\hline \multirow{3}{*}{$\begin{array}{l}\text { [Jostling between } \\
\text { adjacent age-sets } \\
\text { during change-over] }\end{array}$} & 'Firestick' patrons & \multirow{3}{*}{$\begin{array}{l}\text { [Local jostling between } \\
\text { adjacent sub-castes] }\end{array}$} & Kshatriyas as rulers \\
\hline & Novice elders & & Vaishyas \\
\hline & Moran & & Shudras \\
\hline Gross disrespect & $\begin{array}{l}\text { Boys [excluded from } \\
\text { the age- set system] }\end{array}$ & Wholly polluted & $\begin{array}{l}\text { Untouchables } \\
\text { [excluded from the } \\
\text { caste system] }\end{array}$ \\
\hline
\end{tabular}

envelops them in an aura of greatness that elicits the respect of all other sectors of society. To say in Maasai that an old man has 'respect' (enkanyit) is synonymous with saying that 'he is great' (e-kitok). It is the oldest Maasai that are held to be closest to God; and following a decision at any formal meeting of elders, it is a survivor of the most senior age-set present who leads the blessing. The two poles of the Hindu system of extreme purity and extreme pollution are associated with the Brahmans and the Untouchables respectively. In the Maasai example, the two poles of extreme respect and extreme disrespect are associated with unflappable old age and untameable boyhood. The two intellectual systems, which in other ways have so little in common, are both in a sense pegged down firmly at their two extremes, while the dynamics of day to day existence, the political and economic realities, which are secondary for Dumont, take place in the jostling for position in the middle. ${ }^{13}$

13 Dumont 1972: 38, 84, 115; Bailey 1957: 266-7. One is reminded of André Gunder Frank’s (1967) analysis of underdevelopment in South America, in which the system of exploitation and rebellion is perpetuated by the power of international capitalists at the top and the sheer impotence of impoverished peasants at the very bottom. Between these extremes is the fruitless struggle among middle classes who can never surmount the basic system of inequality. 


\subsection{Conclusion: Fundamental Structures and the Premise of Holism}

This comparison between the Maasai and Hindu political systems is an attempt to discern similarities at a deeper structural level, suggesting a more fundamental model of stratification. The obvious contrast between a social system that was essentially immobile and one that had a programmed mobility built into its very core corresponds to two very different premises of inequality: by age and by descent, each strung along a ladder from top to bottom.

Jostling for position on the Maasai age ladder challenges the principle of gerontocratic order, just as jostling on the Hindu caste ladder challenges the principle of ranking and suggests the possibility of a degree of mobility. However, the fact that it is as age-sets and as castes and not as individuals that they jostle confirms the basic hierarchical divisions of each society. Again, the fact that the highest status in each case is firmly pegged on the highest rung of the ladder and that the most despised status is firmly pegged even below the lowest rung provide an overarching perspective to the jostling on the intermediate rungs. They give the jostling a sense of purpose, sustaining the principles on which each ideology is based. The premise of caste hierarchy in the Hindu case and of gerontocracy in the Maasai case underpin the relevance of the jostling for position, which in turn heightens the awareness and importance of status.

Along the Maasai ladder, there is no struggle for the rung occupied by the novice elders while they seek to build up their families and herds. They are in a quiescent period following the struggles for retaining the prime of moranhood, and they are not yet poised for the struggle for firestick patronage. On the other hand, the jostling in the arena of moranhood is so intense that it provides an alternative premise, highlighting the virtue of force over that of diplomacy as a political instrument. While in the longer term, it is the elders' arena and the premise of age inequality that ultimately dominates, there is a third ideology that is becoming increasingly important. This focuses on the wealth of individual elders, whether by luck, good herd management, or opportunism. Wealth is coveted, while the self-induced poverty of wastrels is despised. This is quite independent of the age-set system. Differences in wealth breed jealousy and a concern over sorcery as the epitome of individual greed.

Corresponding to the unorthodoxy of moranhood and inequalities of wealth among the Maasai, alternative hierarchies also colour the Hindu system such as those premised on asceticism or on wealth. ${ }^{14}$ Similarly, there are parallels between other treatments of the Hindu and Maasai political systems. Thus the distribution of power for both the Hindu caste system and the Maasai age system has been explained 
coining the principle that 'Might is Right'. ${ }^{15}$ Or in terms of more subtle manipulation, playing down ideological constraints of the traditional systems. ${ }^{16}$ Or in terms of a Marxist model of exploitation. ${ }^{17}$

These approaches contrast with Dumont's plea for holism in the analysis of the caste system, which he maintains has so often been lacking. ${ }^{18}$ This can be matched with a plea for holism in the study of East African age organizations. There is adequate evidence to suggest that the model presented here applies very generally to other pastoralist societies in East Africa. Yet it is curious that regarding these societies, which so often are among the most resistant to change, we are normally told very little of the way in which each age system relates to other institutions, notably those associated with kinship, marriage and the position of women. It is curious, because the very fact of stability suggests that here at least one may be faced with a system whose parts articulate functionally to form a whole, or at least something as close to a functional whole as we are likely to encounter. Certainly, there has been change with increasing opportunism, but the persistence of the Maasai system throughout the colonial period and beyond (at least for a number of decades) suggests the need for a holistic treatment of the traditional system. The route to elderhood has dominated, step by step, rung by rung, in an endless succession, but taken by itself this evades the problem of explaining how the present has reproduced itself to account for the stability of the traditional system. The next chapter looks more closely at relations within each age-set in an attempt to address this problem.

15 Srinivas 1959; cf. Merker 1904

16 Bailey 1957; cf. Gulliver 1963

17 Beidelman 1959; cf. Rigby 1992

18 Dumont 1972: 75 